\title{
Islam y derechos de la mujer en Marruecos*
}

\author{
Fatiha Benlabbah**
}

\begin{abstract}
Resumen
Para comprender el proceso de emancipación de la mujer marroquí hay que seguir la evolución de sus derechos desde los albores de la Independencia del país. La importante reforma de la Moudawana (Código de Estatuto Civil) de 2004, es el resultado de la implicación efectiva y eficaz de todos los actores, Rey Gobierno y sociedad civil. Como opción modernista y democrática, el nuevo Código de la Familia saca su fuerza de la Chari'a (ley islámica) y se inspira en la dimensión humana y en los principios de los derechos del hombre.
\end{abstract}

Palavras-chave: Derechos de la Mujer, Marruecos, Islam.

\footnotetext{
" Recebido para publicação em dezembro de 2007, aceito em abril de 2008.

** Vice-Directora do Instituto de Estudios Hispano-Lusos da Universidad Mohammed V-Agdal, Rabat, Marruecos. http://iea:um5s:ac.ma

cadernos pagu (30), janeiro-junho de 2008:95-106.
} 
Islam y derechos de la mujer en Marruecos

Islam and Women's Rights in Morocco

\begin{abstract}
To understand the Moroccan women's emancipation process we need to follow the evolution of their rights since Independence. The 2004 crucial reformation of the Moudawana (Civil Code) is the consequence of the effective and efficient mobilization of all agents involved in it: the King, the Government and the Civil society. As a modernist and democratic solution, the new Family Code is inspired by the Sharia (Islamic law) and by Human Rights values.
\end{abstract}

Key Words: Women's Rights, Islam, Family Code. 
Fatiha Benlabbah

Marruecos es un país africano, árabe-musulmán, con 30 millones de habitantes. Es una monarquía constitucional, democrática y social. La Constitución estipula que el Reino de Marruecos es un Estado musulmàn y que el Rey es el representante supremo de la Nación, símbolo de su unidad, garante de la perennidad y de la continuidad del Estado y en cuanto que Amir Al mouminin o Comendador de los creyentes, vela por el respeto de la constitución y del Islam. Amir Al Mouminin es un título islámico tradicionalmente asociado al Califa, que indica que su portador es la máxima autoridad religiosa entre los musulmanes. Tiene como misión, la protección de la fe y el garantizar la libertad de culto para los que profesan otra religión monoteísta. Amir al Moumimin es la única referencia religiosa para la Nación marroquí; ningún grupo o partido puede erigirse en portavoz o tutor del Isalm. La función religiosa emana del hecho que Amir Al Mouminin es el Imam (jefe religioso) Supremo.

La constitución determina también los deberes del ciudadano y garantiza sus derechos y libertades (libertad de asociación, de manifestación pública, de prensa, libertad sindical). Marruecos preconiza la ciudadanía activa. Ser ciudadano implica la posibilidad y la responsabilidad para mejorar el mundo en que vivimos; implica participación, acción, compromiso y aportación personal para la edificación democrática colectiva que es una obra de todos y de cada día.

Desde hace 14 siglos, los marroquíes han elegido adoptar el Islam. Es una religion del justo medio que se basa en la tolerancia, honora la dignidad humana, preconiza la coexistencia y rechaza la violencia, el extremismo y la busqueda del poder por medio de la religion. A la luz de esto, nuestros antepasados edificaron una civilizacion islàmica y un estado independiente (del Califato del Machrek), distinguiéndose por su apertura en materia de culto, por la exclusividad del rito malekita y por su apego a la Imarat al Muminin. 
Islam y derechos de la mujer en Marruecos

El malikismo es una de las cuatro escuelas jurídicas sunníes clàsicas (Hanifismo, Chafeismo, Hanbalismo). Porque condiciona y determina nuestra religiosidad, hablaré brevemente de algunas de sus características. Se caracteriza el rito malekita por salvaguardar a la vez la salvacion de la comunidad en lo temporal y el destino de los creyentes de cara al màs allà. En este sentido, se distingue por la búsqueda del equilibrio entre la ambición del individuo y la indispensable cohesión y progersión de la Umma o comunidad, por la moderación, la flexibilidad, la tolerancia, la apertura a la realidad y el esfuerzo de interpretación y adaptación, a partir de un referente ortodoxo que en àrabe llamamos Ijtihad.

Los marroquíes lo han enriquecido con aportaciones que emanan de ese esfuerzo imaginativo del ljtihad, dando así pruebas de esa moderación que corre pareja con la esencia misma de la personalidad marroquí que està en perpetua interacción con las culturas y las civilizaciones. Partiendo de esta visión clarividente de nuestro referente religioso, islam y modernidad se complementan para formar afluentes fundamentales que irrigan el referente universal, en perfecta armonía con la democracia, base $y$ fundamento de la monarquía constitucional marroquí.

Partiendo de esta visión del islam y del respeto de los valores de la democracia y de los fundamentos de la ciudadanía, Marruecos, como país que aspira al progreso y a la modernidad sin renegar de la tradición, ha hecho de la promoción de las mujeres, que constituyen la mitad de la población, un objetivo prioritario.

La mujer marroquí ha alcanzado un grado de emancipación y participación ciudadana ejemplares en el mundo árabe-islámico. Ocupa hoy masivamente la esfera pública: hay mujeres con altos cargos políticos: una consejera del rey, ministras, diputadas, una alcaldesa. Hay también rectoras de universidad, decanas, policías, directoras de cine, escritoras, académicas, catedráticas, investigadoras, periodistas, presidentas y dirigentes de empresas, y de asociaciones, etc. El número de estudiantes universiatrios de sexo femenino supera con creces a veces él de los chicos. Esto es 
Fatiha Benlabbah

el resultado merecido de un largo y dificil recorrido. La histotria se construye peldaño por peldaño. Los logros de hoy son el fruto de una lucha constante, contra mareas y vientos; pero también de la voluntad política de los dirigentes, desde la independencia del país en 1956.

El movimiento para la emancipación de la mujer marroquí en sus albores se inscribió en el marco general del gran movimiento para la liberación del país del yugo del protectorado y de la colonización. La lucha para la emancipación de la mujer era vista como una muestra, una manifestación del nacionalismo de los marroquíes. Nacionalismo y feminismo corrían parejos. Desde los comienzos de la lucha para la independencia, en los años cuarenta del siglo pasado, los partidos políticos crearon, en su seno, células femeninas paralelas: el partido comunista creó la Unión de las Mujeres marroquíes; el partido del istiqlal, la Sección femenina (1944); en 1947 apareció la primera asociación femenina, "Las hermanas de la pureza"; en ese mismo año, la entonces joven y moderna princesa Lalla Aicha, por instrucciones de su padre Mohammed V, pronunció en Tánger, un discurso histórico en el cual por primera vez se hacía alusión a la independencia de Marruecos, erigiéndose así la princesa (que luego, en los años 60, será nombrada embajadora), en símbolo de la emancipación de la mujer marroquí.

El estudio del discurso feminista reformista de la época, visto desde el presente, nos parece realmente muy adelantado con respecto a su época. Las militantes de los años cuarenta del siglo pasado, denunciaban las formas de discriminación contra ellas y reivindicaban derechos sociales, tales como la escolarización, la preservación de la dignidad de la mujer, una protección social y condenaban la poligamia. Más aún tuvieron el valor en cierta ocasión de dirigirse a los Ulemas reclamando igualdad con el hombre y argumentando que, si como lo afirman los Ulemas, el islam ha instituido una Constitución con derechos de la mujer para todas las épocas y las sociedades, garantizándole dignidad y rango social, haciendo de ella la igual del hombre, ¿́por qué 
Islam y derechos de la mujer en Marruecos

entonces, se privilegia a éste y se la discrimina a ella en asuntos como el testimonio, el repudio, etc.?

A pesar del retroceso con respecto a esos logros que supuso la promulgación en 1957 de la Moudawana o Código del Estatuto Personal, basado en una interpretación muy rígida de la Chari'a (Ley islàmica), de la que resultaba una consolidación de la desigualdad en el seno de la familia, las aspiraciones femeninas a conseguir derechos sociales y políticos (garantizados por la constitución desde 1962) y la superación de la desigualdad en el seno de la familia, se mantuvieron vivas y firmes, diría incluso que han sido estimuladas y avivadas por unas circunstancias determinantes desde principios de los años setenta. Estas circunstancias consistían em la aparición de las mujeres progresistas, sindicalistas, y en el compromiso ideológico de las estudiantes que, a partir de los años sesenta, militan al lado de los estudiantes en el seno de la universidad.

Todo esto tenía que producir el decisivo giro que conoció el movimiento femenino marroquí en los años ochenta de la centuria pasada: la dimensión decididamente feminista del movimiento la revela el importante número de asociaciones, ONGs, grupos de investigación universitarios, periódicos y revistas especializadas. Acción y reflexión. La investigación sociológica y los estudios jurídicos corren parejos con una producción literaria caracterizada por una evidente dimensión testimonial, que da cuenta de la situación de la mujer desde todos los puntos de vista. Toda esta producción científica y literaria servía para dar argumentos a favor de los derechos de la mujer y justificar la necesidad de superar los bloqueos y las resistencias que obstaculizaban la emancipación de la mujer marroquí. El Código de Estatuto Personal, redactado en los años cincuenta, constituía un freno a una verdadera emancipación femenina. Las mujeres respaldadas por feministas hombres, organizaron desde los años ochenta su acción con el fin de lograr la reforma de ese texto que parecía anacrónico.

Tratar de la Moudawana o Código de la Familia, nos obliga, entonces, a preguntarnos por: 
Fatiha Benlabbah

1) el largo proceso que condujo a la Reforma,

2) los diferentes discursos producidos y las posiciones manifestadas. Porque lo que estaba en juego era problemàtico, tratàndose de una sociedad que se aferra a la tradición y aspira firmemente a la modernidad,

3) las consecuencias de la Reforma de la Moudawana sobre la sociedad marroquí.

En efecto, entre 1992 y 2004, se produjeron acontecimientos de gran envergadura en Marruecos:

1) en 1992 las asociaciones y grupos de investigación sobre la mujer, se unen para reclamar la reforma de la Moudawana. Lanzan una acción denominada "un millón de firmas". El apoyo popular ha sido enorme y violenta fue la reacción de los conservadores;

2) En 1993 Marruecos ratifica la convención Internacional para la eliminación de todas las formas de discriminación contra la mujer;

3) En 1993, en tiempos del rey Hassan II, se consigue la primera, aunque limitada, revisión del Código del Estatuto Personal;

4) En 1998 el gobierno propone una estrategia global cuyo objetivo es reforzar la promoción y la participación de la mujer en el desarrollo. Se trata del Plan de Acción Nacional para la Integración de la Mujer en el Desarrollo del país, plan respaldado por las Naciones Unidas. Las propuestas de enmienda del Estatuto personal que el plan contenía provocaron reacciones en contra. Hubo una movilización sin par, tanto de las fuerzas progresistas como de las conservadoras, lo cual dió lugar a dos grandes manifestaciones paralelas, una a favor del plan, en las calles de Rabat, la capital política, la otra en contra, en Casablanca, la capital económica. El enfentamiento y el desacuerdo hicieron que se pusiese en vela el proyecto de integración de las mujeres en el desarrollo. Pero los debates engendrados en torno a él han sido en 
Islam y derechos de la mujer en Marruecos

realidad reveladores y muy edificantes para la opinión pública en general y para los dirigentes políticos, en particular;

5) La dinàmica engendrada por la Red de apoyo al Plan Nacional de Acción para la integración de la mujer en el Desarrollo del país, (1999 a 2002) y la red "Primavera de la igualdad", (2001-2003): las asociaciones se unieron para llevar a cabo una acción común de gran envergadura, proponiendo alternativas bien meditadas con argumentos sociológicos, jurídicos, de derechos humanos universales y de fikh o derecho musulmán. El mensaje de las asociaciones era que:

a. la sociedad marroquí ha cambiado, y la ley ha de acompañar esos cambios y propiciar el bienestar de los individuos y de la colectividad;

b. el derecho musulmán es el producto de un contexto histórico y sociológico (siglo VIII) y que no podía constituir un marco suficiente para aportar respuestas a las situaciones complejas de hoy.

6) El rey Mohammed VI toma la iniciativa histórica de reformar el texto de la Moudawana, creando primero, para ello una comisión consultativa, formada por hombres y mujeres de distintas tendencias y especialidades. El arbitraje del Rey, práctica genuina y particular en Marruecos, ha permitido sacar el debate fuera del enfrentamiento obtuso entre progresistas $y$ conservadores y así avanzar hacia la reforma deseada de la Moudawana.

\section{El nuevo Código de Familia marroquí}

El cambio que supuso la reforma de la Moudawana lo refleja, en primer lugar, el cambio de denominación, Del Código del Estatuto Personal se pasa al Código de la familia:

El código de la familia no debería considerarse como una ley dictada especialmente para la mujer sino màs bien como un dispositivo destinado a toda la familia y que obedece a una preocupación doble: la de superar la 
Fatiha Benlabbah

injusticia que padecen las mujeres y la de proteger los derechos de los niños y de preservar la dignidad human (Discurso Real, octubre 2003, en el Parlamento)

Las disposiciones que tienen un caràcter religioso compiten exclusivamente a Amir Al Mouminin. Pero el Código de la Familia, contiene obligaciones civiles, por eso el Rey decidió someter el proyecto al Parlamento, lo cual permitió que la Moudawana fuera incluida en el corpus legislativo.

Qué ha aportado el nuevo Código?

Se introducen nuevos conceptos, como el de la corresponsabilidad. Se consagra la igualdad de la mujer con respecto al hombre $y$ se instaura el divorcio por mutuo consentimiento.

- Corresponsabilidad: la familia está ahora situada bajo la responsabilidad conjunta de los dos esposos y ya no bajo la responsabilidad exclusiva del marido. La regla de "la obediencia de la esposa al marido" queda eliminada;

- La tutela: la mujer ya necesita de un tutor (wali) para casarse, lo cual era obligatorio en el texto anterior;

- La edad del matrimonio queda fijada en 18 años tanto para la mujer como para el hombre, en vez de 15 años;

- La poligamia: no desaparece pero el nuevo texto la somete a condiciones que casi la hacen imposible. La mujer tiene ahora el derecho de poner condición a su matrimonio: que el marido se comprometa a no casarse con otras mujeres. Además, el marido precisa ahora de la autotrización del juez para contraer matrimonio con una segunda mujer;

- El repudio: queda sometido a la autorización previa del juez; antes era el derecho exclusivo del marido;

- El divorcio: la mujer puede pedir el divorcio. Antes el juez sólo aceptaba la solicutudo de divorcio presentada por la mujer en casos excepcionales, cuando ésta presentaba pruebas de perjuicios padecidos y testigos; 
Islam y derechos de la mujer en Marruecos

- La guarda de los niños: en caso de divorcio, la guarda de los niños corresponde primero a la madre, luego al padre, luego a la abuela materna. La guarda de los niños requiere un hábitat decente y una pensión alimenticia;

- Los niños nacidos fuera del matrimonio: ahora se protege y garantiza el derecho del niño a la paternidad en caso de no formalización del matrimonio por un acto escrito. Antes la regla era el no reconocimiento del niño

- La repartición de los bienes: el nuevo texto ofrece a los esposos la posibilidad de establecer un contrato antes del matrimonio para la gestión de los bienes adquiridos

- La herencia de los niños: ahora éstos tienen el derecho de heredar de su abuelo materno también.

Los resultados de la reforma del Estatuto Personal de la mujer han sido inmediatos: los divorcios denominados jol' (la mujer paga una compensación económica al marido para conseguir el divorcio) han bajado de un $72 \%$; se registra un auge del talaq chiqaq o "procedimiento de desunión", un tipo de divorcio que supone o implica derechos económicos para la mujer; una disminución de los expedientes de repudio (la cuantía de las pensiones relativas a los hijos es elevada), un aumento de las demandas de divorcio presentadas por mujeres en un $41 \%$. La reforma de la Moudawana ha favorecido también, un desbloqueo de la situación política de las mujeres, un cambio en el comportamiento de los partidos políticos: tal es el punto de vista de una diputada que fue designada presidente de un grupo parlamentario.

Sin embargo, el nuevo código es susceptible de perfeccionamiento. Los actores sociales y las autoridades estatales están todos implicados para una mejor aplicación de la ley y para el logro de derechos pendientes, como el de la nacionalidad. Los obstáculos que existen, reflejan cierta deficiencia institucional y también los lastres socio-culturales del país: condicionamientos de las convenciones sociales, reflejo de la estructura patriarcal 
Fatiha Benlabbah

marroquí propia de una sociedad conservadora. Los esfuerzos para superar tales obstáculos son múltiples: creación de 60 juzgados de familia, acompañamiento y seguimiento por parte de la sociedad civil mediante investigaciones en el terreno que dan lugar a informes edificantes. Por otro lado, el gran Plan Nacional para el Desarrollo Humano, es una verdadera plataforma que puede garantizar la consolidación de los derechos logrados.

La dinàmica generada por la reforma de la Moudawana refleja el grado de responsabilidad de todos los actores implicados. Para hacerla efectiva, la sociedad civil la acompaña con instrumentos didácticos de difusión. Se trata de una labor realizada por algunas asociaciones. Citaremos por ejemplo:

1) el CDROM trinlingue, arabe, Amazigh y francés (se puede consultar la siguiente página web http.connaistesdroits.tanmia.ma)

2) Seis tebeos "Racontez moi le nouveau code de la famille", realizado en partenariado entre "Leaderschip feminine", la "Association cadre" y el "Réseau des associations de développement" (RADEV). Redactados en àrabe dialectal y en francés, estos tebeos estàn destionados, en primer lugar, a los jóvenes arabófonos y francófonos con menos de 12 años de edad. La colección trata de la corresponsabilidad de los dos esposos en la gestión de los asuntos del hogar, la edad para el matrimonio, la poligamia, el divorcio, la pensión alimenticia, la tutela, los bienes adquiridos durante el matrimonio $y$ las modalidades de compatirlos.

Esta estrategia de acompañamiento y de difusión de la Moudawana reformada, mira hacia el futuro. El derecho y el deber de ciudadanía implican un conocimiento adecuado de los derechos y obligaciones y requieren una participación activa en los asuntos del país, la cual está supeditada a lo anterior.

\section{Conclusión}

El nuevo Código de la Familia corresponde a una elección modernista y democrática. Saca su fuerza de la Chari'a y se 
Islam y derechos de la mujer en Marruecos

inspira en la dimensión humana y en el espíritu de las leyes internacionales. Se inspira en los principios de los derechos del hombre y en los valores del Islam. El Rey insistió en la necesidad de inspirarse en los designios del Islam tolerante que honra al hombre y preconiza la justicia, la igualdad y la cohabitación armoniosa, de apoyarnos en la homogeneidad del rito malekita así como en el ljtihad que hace que el islam sea una religión adaptada a todas las épocas.

Es una reforma excepcional por su ambición y su alcance. Lo que estaba en juego con su revisión no era sólo nacional sino internacional y civilizacional. De ahí que se hayan escuchado voces en algunos países árabes deseando para sí también una reforma similar, unos derechos garantizados como estos derechos que la Moudawana nos garantiza.

Inauguraba una nueva era para la mujer y abría grandes e importantes perspectivas para el niño, el hombre y la familia en general. Ha situado la cuestión de la mujer sobre una plataforma de progreso y desarrollo. Ha establecido un marco legal favorable para su igualdad respecto del hombre.

Es una piedra angular de la modernización social y símbolo del cambio que conoce Marruecos. Es y serà para la historia del pueblo marroquí un gran acontecimiento portador de un cambio realmente decisivo. 